\title{
Diabetes remission: a realistic goal?
}

Four years ago, Professor Nick Finer and I wrote an editorial in Clinical Medicine calling for concerted national action to prevent the epidemic of diabetes in the UK. ${ }^{1}$ Since then, the growing burden of type 2 diabetes (T2D) nationally and internationally remains unabated. ${ }^{2,3}$ In the UK, one in 10 men are diagnosed with the condition ${ }^{4}$ and growth in prevalence of T2D appears to be following most modelling predictions, with currently 4 million people diagnosed, rising to 5.5 million by 2025 . $^{2}$ Internationally, countries at the forefront of rapid economic development (such as China and India) are the ones that are bearing the most rapid rise in the burden of T2D. ${ }^{3}$

Preventing T2D in high-risk people is feasible. ${ }^{5,6}$ However, such interventions are costly and labour intensive. The current political and economic focus in the UK is with Brexit, and as a result, healthcare and in particular public health, have received scant attention. Two recent initiatives, however, may offer some hope. Firstly, the NHS Diabetes Prevention Programme (NHSDPP) which is a programme collaboration between NHS England, Public Health England and Diabetes UK aiming to intervene in people with high risk for developing diabetes (prediabetes) using a behavioural change programme to reduce weight. ${ }^{7}$ There is some robust evaluation planned, which is a welcome change to other initiatives (such as 'Change 4 Life') which have little or no evidence behind them. ${ }^{8}$ Secondly, in one of his final acts as chancellor of the exchequer, George Osborne planned the introduction of a 'sugar tax' to limit sugar-sweetened soft drink consumption. The tax has been confirmed by the current chancellor in his recent budget, whereby drinks with more than 5 grams of sugar per $100 \mathrm{~mL}$ will be levied by $18 p$ per litre, while those with 8 grams or more of sugar per $100 \mathrm{~mL}$ will have an extra tax of $24 \mathrm{p}$ per litre. ${ }^{9}$ Commencing from 6 April 2018, income derived from this tax will be given to the Department for Education to help fund school sports. There is good evidence from others countries such as Mexico that this may have a significant impact on sugar-sweetened beverage consumption in children, particularly in households with lower incomes. ${ }^{10}$ Encouragingly, a number of drinks manufacturers have reduced the sugar content of their drinks in anticipation of the tax.

While both of these initiatives are welcome, they probably lack the scope or impact to make significant inroads into the public health crisis of rising diabetes prevalence.

More recent interest has been focused on intervening to aid weight loss in patients with recently diagnosed T2D. A recently published study from researchers in Scotland and Newcastle undertook a 'real world' intervention to aid weight loss in relatively recently diagnosed (under 6 years), obese patients with T2D (149 in the intervention group and 149 in the control group). ${ }^{11}$ The intervention took place in primary care surgeries (cluster randomised), delivered by trained practice nurses or dietitians. The intervention offered total food replacement with nutritionally balanced dietary supplements (approximately $800 \mathrm{kcal}$ per day) to patients with T2D for a period of 12 weeks. This was followed by a 4-week food reintroduction phase and a further weight maintenance phase up to 2 years, using diet and exercise programmes to try to prevent weight regain. Mean weight of the cohort was around $100 \mathrm{~kg}$ (body mass index around $35 \mathrm{~kg} /$ $\mathrm{m} 2$ ), and median duration of diabetes was 3 years. Twelve month follow-up data shows remarkable results: $24 \%$ of the intervention group lost $15 \mathrm{~kg}$ or more and $50 \%$ lost $10 \mathrm{~kg}$ or more. Median weight loss was $10 \mathrm{~kg}$ in the intervention, and $1 \mathrm{~kg}$ in the control. Of the intervention group, $46 \%$ had remission of their diabetes, compared to $4 \%$ of the control group.

There are many unanswered questions, such as will the lost weight be regained, what is the effect in other ethnic groups ( $99 \%$ of the cohort were white), is the intervention cost effective and sustainable, and is there an effect in people with longer duration of diabetes? Nevertheless, these data suggest that the focus for diabetes care, at least in the early phase of the disease, should be on weight reduction, which might lead to remission of the condition. ${ }^{12}$ Indeed, we now have a number of pharmacological interventions which aid weight loss in T2D and perhaps their place in therapy might be earlier than drugs such as insulin or sulfonylureas, which cause significant weight gain. ${ }^{13}$

Diabetes prevention in the UK is making baby steps towards some sort of public health policy focused on improving diet and exercise. The glaring omission remains a substantive policy towards tackling childhood obesity. The published UK government guidance on tackling childhood obesity has been widely regarded as not going far enough to curb obesity in children. ${ }^{14}$ One can only hope that more substantial steps will be taken in the future once the Brexit dust has settled.

\section{References}

1 Chowdhury TA, Finer N. Preventing diabetes: a call for concerted national action. Clin Med 2013;13:328-9.

2 Diabetes UK. Diabetes facts and stats. https://diabetes-resourcesproduction.s3-eu-west-1.amazonaws.com/diabetes-storage/ migration/pdf/DiabetesUK_Facts_Stats_Oct16.pdf [Accessed 13 December 2017].

3 International Diabetes Federation. The IDF Diabetes Atlas - 8th edition. www.diabetesatlas.org/across-the-globe.html [Accessed 13 December 2017].

4 Men's Health Forum. One in Ten: the male diabetes crisis. London: Men's Health Forum, 2017. https://www.menshealthforum.org.uk/ one-ten-male-diabetes-crisis [Accessed 13 December 2017].

5 Knowler WC, Barrett-Connor E, Fowler SE et al. Reduction in the incidence of type 2 diabetes with lifestyle intervention or metformin. N Engl J Med 2002;346:393-403.

6 Tuomilehto J, Lindstrom J, Eriksson JG et al. Prevention of type 2 diabetes mellitus by changes in lifestyle among subjects with impaired glucose tolerance. N Engl J Med 2001;344:1343-50.

7 NHS England. The NHS Diabetes Prevention Programme. www.england.nhs.uk/diabetes/diabetes-prevention/ [Accessed 13 December 2017]. 
8 Editorial. Change4Life brought to you by PepsiCo (and others). Lancet 2009;373:96

9 HM Revenue and Customs. Guidance: Soft Drinks Industry Levy. https://www.gov.uk/guidance/soft-drinks-industry-levy [Accessed 13 December 2017].

10 Colchero MA, Molina M, Guerrero-López CM. After Mexico implemented a tax, purchases of sugar-sweetened beverages decreased and water increased: Difference by place of residence, household composition, and income level. J Nutr 2017;147:1552-7.

11 Lean ME, Leslie WS, Barnes AC et al. Primary care-led weight management for remission of type 2 diabetes (DiRECT): an open-label, cluster-randomised trial. Lancet 2017;391:541-51.

12 Uusitupa M. Remission of type 2 diabetes: mission not impossible. Lancet 2017;391:515-6.
13 Chowdhury TA, Grant PS. Drug therapies in type 2 diabetes: an era of personalised medicine. Clin Med 2016;16:441-7.

14 Government HM. Childhood obesity: a plan for action. HM Government, 2016. www.gov.uk/government/uploads/system/ uploads/attachment_data/file/546588/Childhood_obesity_2016_2_acc.pdf [Accessed 13 December 2017].

Tahseen A Chowdhury Address for correspondence: Professor Tahseen A Chowdhury, Department of Diabetes and Metabolism, 7th Floor, John Harrison House, The Royal London Hospital Whitechapel, London E1 1BB, UK. Email: Tahseen.Chowdhury@bartshealth.nhs.uk
'This landmark report lays out in the starkest terms yet the devastating impact air pollution is having on our health, our economy and our society as a whole.'

\section{Every breath we take The lifelong impact of air pollution}

This major report plainly sets out the dangerous impact that air pollution has on our nation's health. Compiled by experts in medicine and environmental sciences, the report discusses the current evidence and draws up recommendations for action.

ISBN 978-1-86016-567-2 £15 including $p+p$ or free to download

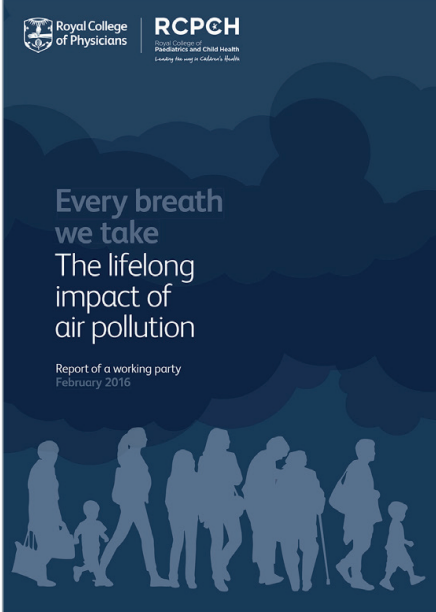

Order a copy: shop.rcplondon.ac.uk 